\title{
Productivity measurement using DEA and Malmiquest index
}

\author{
Alireza Khosravi ${ }^{a^{*}}$, Sayed Ismail Najafi ${ }^{\mathrm{b}}$ and Saeed Rafiei ${ }^{\mathrm{c}}$
}

${ }^{a}$ Department of Science in Industrial Engineering, Qeshm International Branch, Islamic Azad University, Iran

${ }^{b}$ Assistant Professor, Department of Industrial Management, Qeshm International Branch, Islamic Azad University, Iran

${ }^{c}$ Manager of the company, Tehran, Iran

\begin{tabular}{l}
\hline C H R O N I C L E \\
\hline Article history: \\
Received March 25, 2015 \\
Received in revised format 28 \\
March 2015 \\
Accepted 15 May 2015 \\
Available online \\
May 182015 \\
\hline Keywords: \\
Performance assessment \\
Productivity index \\
Malmquist \\
DEA
\end{tabular}

\begin{abstract}
A B S T R A C T
Performance measurement is one of the primary tasks in every organization and it helps organization setup appropriate targets for future. There are several ways to assess the performance of the organization, and data envelopment analysis (DEA) is one of the most important methods. DEA is an appropriate technique to measure the efficiency of decisionmaking units, but does not provide complete information about the unit's productivity. Malmquist productivity index is one of the methods for measuring productivity and the main advantage of this index is the possibility of the productivity changes over time. In this study, DEA is used to measure service performance and economic foundation so that the performance of four companies within a 3-month period were evaluated. In this work, the cost of the system and investment were used as inputs, revenue and profit were considered as the output and constant returns to scale (CCR) was used to analyze the system, which yields 0.9 for all units when all input/output data were considered in crisp form. The efficacy of different units using interval data also showed different productivity compared with the crisp model. The productivity measures of the companies in three-month period were studied using the Malmquist based productivity index and the results were analyzed.
\end{abstract}

\section{Introduction}

For years, there have been extensive attempts to use data envelopment analysis (DEA) for measuring the relative efficiency of similar unit (Charnes et al., 1978; Banker et al., 1984). DEA technique is commonly used when input/output cannot be measured by using financial figures. For instance, in educational services, one may be interested in promoting schools with students who achieve academic excellence. Many providers of electricity in the world lose money due to several reasons and governments may assign additional budgets based on non-financial figures such the number customers covered, the volume of electricity transmitted, etc. In a DEA method, there are some inputs/outputs related to all decision-making units. Let $x_{i j}$ be the inputs for one of decision-making unit with $i=1, \ldots, m$ and $y_{r j}$ be the outputs of the same units with $r=1, \ldots, s$ and $j=1, \ldots, n$ and suppose $u_{i}$ and $v_{j}$ are the dual

\footnotetext{
* Corresponding author. Tel: +98-912-1269518

E-mail address: khosravi55alireza@yahoo.com (A. Khosravi) 
variables associated with $x_{i}$ and $y_{j}$, respectively. The constant return to scale DEA model is formulated as follows,

$$
\begin{array}{cc}
\max & \\
\text { subject to } & \frac{\sum_{r=1}^{s} u_{r} y_{r} .}{\sum_{i=1}^{m} v_{i} x_{i} .} \\
& \frac{\sum_{i=1}^{s} v_{r} y_{r j}}{\sum_{i} x_{i j}} \leq 1 . \\
x_{i j}, y_{i j \geq 0}
\end{array}
$$

Model (1) is the original DEA, which can be solved $j$ times to measure the relative efficiencies of various units. However, since model (1) is nonlinear in structure, Charles et al. (1978) proposed a method to convert model (1) into a simple linear programming problem as follows,

$$
\begin{array}{ll}
\max & z=\sum_{r=1}^{s} u_{r} y_{r .} \\
\text { subject to } & \frac{\sum_{r=1}^{s} u_{r} y_{r j}}{} \\
& \sum_{i=1}^{m} v_{i} x_{i j} \\
& \sum_{i=1}^{m} v_{i} x_{i .}=1 \\
& u_{r}, v_{i} \geq 0, \quad j=1, \ldots, n
\end{array}
$$

The Malmquist Index is a total factor productivity index based on distance functions, relative to the previous year (Caves, 1982). One of the primary advantages of Malmquist index is that it would not involve the producer's behavior optimization assumption and these units can be deficient (Tulkens, 1993). Besides, this index uses non-parametric DEA method (Rezitis, 2006), which measures total factors productivity change at two time point by using interval function. To explain this index, we examine Fig. 1.

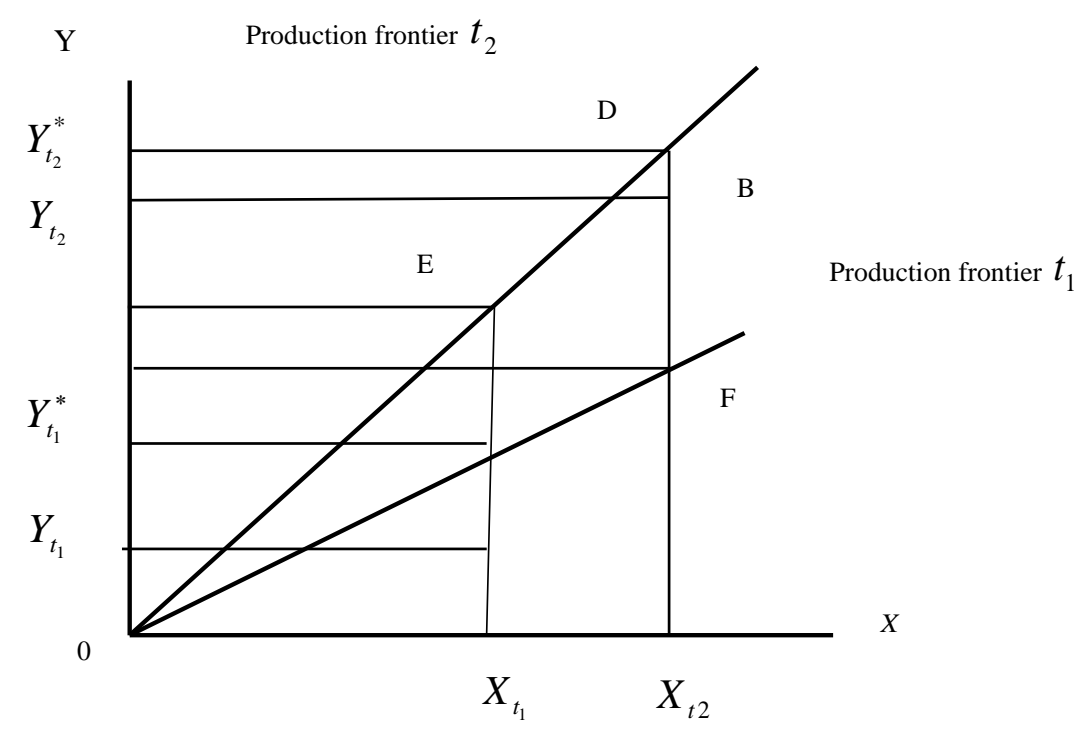

Fig. 1. Description of Malmquist index productivity

Fig. 1 examines a simple state, which incorporates a saving used for producing a production. Let $\left(X_{t}^{1}, Y_{t}^{1}\right)$ and $\left(X_{t}^{2}, Y_{t}^{2}\right)$ be the production in period $t_{1}$ and $t_{2}$, respectively. Malmquist index can be expressed as follows, 


$$
M_{o}^{t}=\left(X^{t+1}, Y^{t+1}, X^{t}, Y^{t}\right)=\frac{D_{o}^{t+1}\left(X^{t+1}, Y^{t+1}\right)}{D_{o}^{t}\left(X^{t}, Y^{t}\right)} \times\left[\frac{D_{o}^{t}\left(X^{t+1}, Y^{t+1}\right)}{D_{o}^{t+1}\left(X^{t+1}, Y^{t+1}\right)} \times \frac{D_{o}^{t}\left(X^{t}, Y^{t}\right)}{D_{o}^{t+1}\left(X^{t}, Y^{t}\right)}\right]^{\frac{1}{2}} .
$$

The first part represents the efficiency changes and the second part expresses the technology changes and the productivity is a result of multiplying efficiency by technology. Malmquist productivity index and its parts are measured under the assumption of a fixed return to scale. When $M_{o}>1$ we have improvement on productivity and once $M_{o}<1$ we experience a decrease on productivity.

There are several applications of Malmquist productivity index (Aparicio et al., 2013; Kerstens \& Van de Woestyne, 2014). Woo et al. (2015) investigated the environmental efficiency of renewable energy from the static as well as the dynamic perspective in 31 OECD countries to learn more about the effect of renewable energy across countries. In their survey, DEA method was applied to measure environmental efficiency through multiple inputs and outputs. In addition, to compute the dynamic environmental efficiency of renewable energy, the Malmquist productivity index was implemented to forecast the average efficiency change.

Wijesiri and Meoli (2015) applied a DEA based Malmquist technique to study the changes in productivity of 20 Kenyan microfinance institutions (MFIs) over the period 2009-2012. A bootstrap procedure was also used to determine whether the changes in Malmquist index and its components were statistically significant. Their results indicated that MFIs had experienced about $7 \%$ annual productivity progress on average. Another bootstrapped regression analysis was also used to study the effect of several environmental variables on productivity change measures and the results indicated that matured MFIs maintained a lower productivity compared to their younger counterparts. Lin and Du (2015) contributed to the existing literature on the methodology of modeling the dynamic of carbon emission performance. They developed a parametric Malmquist index approach that takes into account statistical noises and applied the fixed-effect panel stochastic frontier model to deal with regional heterogeneity. The method was applied to investigate the dynamics of carbon emission performance in 30 Chinese provinces.

Fuentes and Lillo-Bañuls (2015) analyzed the productivity growth of the SUMA tax offices located in Spain evolved over the period 2004-2006 using Malmquist Index based on DEA models. Zhang et al. (2015) proposed a Malmquist $\mathrm{CO}_{2}$ emission performance index (NMCPI) for measuring dynamic changes in total-factor $\mathrm{CO}_{2}$ emission performance over time. The results indicated that the total-factor carbon emission performance of the transportation industry as a whole decreased by $32.8 \%$ over the period, and this reduction was because of technological decline. Gharneh et al. (2014) used bootstrapping Malmquist index to derive the productivity levels of Iranian steam power plants over the period of 2007-2012. Their research indicated that the average level of productivity significantly decreased. It was also reported that technological changes had more effects on productivity than efficiency changes. Ahn and Min (2014) evaluated the multi-period operating efficiency of international airports using DEA and the Malmquist productivity index.

\section{The proposed study}

All activities carried out in this study are in data associated with the service and the economic foundation of an organization with four sub-firm called A, B, C and D in this study. The three-month period (season) for each company is considered as a decision-making unit (DMU) to include all seasonal fluctuation. The period under review was from the beginning of March 2008 to the end of the September 2013, which covers 22 firm-period data ending us to have 88 decision-making unit (DMU) in computing performance. Fig. 1 demonstrates the summary of input/output for DEA method. 


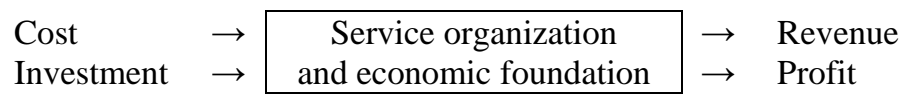

Fig. 2. The input/output of DEA method

As we can observe from the structure of Fig. 2, cost of production and services and investment are considered as inputs of the model and revenue and net profit are considered as the output of the model. The proposed study of this paper uses both Malmquist and DEA method using interval and crisp data. The implementation of the Malmquist uses the following notation:

$$
\begin{aligned}
& M^{++}=\left\{D M U_{j} \mid M I_{j}^{L}>1\right\} \\
& M^{-}=\left\{D M U_{j} \mid M I_{j}^{U}<1\right\} \\
& M^{+}=\left\{D M U_{j} \mid M I_{j}^{L}<1 ، M I_{j}^{U}>1\right\}
\end{aligned}
$$

The $\mathrm{M}++$ set consists of the DMUs performed well between the intervals of the $t$ and $t+1$. The $\mathrm{M}^{-}$set includes DMUs that performed poorly under any circumstances and finally $\mathrm{M}^{+}$set contains DMUs, which did poorly from period t to $t+1$ in some areas. Using the results of DEA method and Eqs. (7-9) we may setup the following for the first firm, A.

$$
\begin{aligned}
& M^{++}=\{Y 13-Y 14, Y 21-Y 22, Y 32-Y 33, Y 51-Y 52, Y 53-Y 54\} \\
& M^{-}=\{Y 43-Y 44, Y 52-Y 53, Y 54-Y 61\} \\
& M^{+}=\{Y 14-Y 21, Y 22-Y 23, Y 31-Y 32, Y 33-Y 34, Y 34-Y 41, Y 41-Y 42, Y 42-Y 43, Y 44-Y 51, Y 61-Y 62\}
\end{aligned}
$$

\begin{tabular}{|c|c|c|c|c|c|c|c|c|c|c|c|c|c|c|c|c|c|}
\hline & 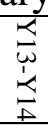 & 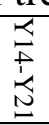 & 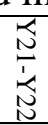 & $\begin{array}{l}\underset{N}{N} \\
\stackrel{\sim}{\sim} \\
\text { W }\end{array}$ & 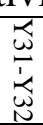 & 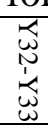 & 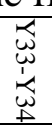 & 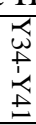 & 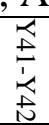 & 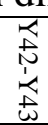 & 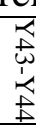 & 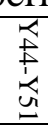 & 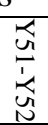 & 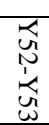 & 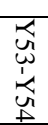 & 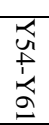 & 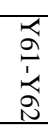 \\
\hline Accurate & + & - & + & 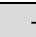 & - & + & - & + & - & - & 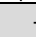 & + & + & - & + & - & + \\
\hline Interval & + & - & + & . & - & + & - & + & - & - & . & - & + & - & + & - & - \\
\hline
\end{tabular}

Table 1 demonstrates the summary of trends for different periods of firm A. As we can observe from the results of Table 1, during some periods, there were some declines on productivity in most periods.

Table 1

The summary of trend in productivity for the first firm, A in different periods

Similarly, we may use Eq. (7-9) to observe the productivity improvement for the second firm, B, which yields,

$$
\begin{aligned}
& M^{++}=\{Y 11-Y 12, Y 12-Y 13, Y 24-Y 31, Y 32-Y 33, Y 43-Y 44, Y 61-Y 62\} \\
& M^{-}=\{Y 13-Y 14, Y 41-Y 42, Y 42-Y 43, Y 52-Y 53\} \\
& M^{+}=\{Y 14-Y 21, Y 21-Y 22, Y 22-Y 23, Y 23-Y 24, Y 31-Y 32, Y 33-Y 34, Y 34-Y 41, Y 44-Y 51, Y 51-Y 52\}
\end{aligned}
$$

\begin{tabular}{|c|c|c|c|c|c|c|c|c|c|c|c|c|c|c|c|c|}
\hline & $\underset{⿱ ऍ}{\leftrightarrows}$ & 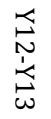 & 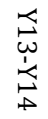 & 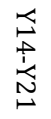 & $\underset{\stackrel{N}{\sim}}{\stackrel{\sim}{N}}$ & 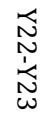 & $\begin{array}{l}\underset{\sim}{\sim} \\
\underset{\sim}{\sim} \\
\stackrel{D}{\sim}\end{array}$ & 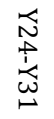 & 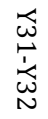 & $\begin{array}{l}\underset{\omega}{\omega} \\
\stackrel{\omega}{\omega} \\
\omega\end{array}$ & $\begin{array}{l}\underset{\omega}{w} \\
\underset{\omega}{\omega} \\
\underset{p}{\infty}\end{array}$ & 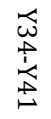 & 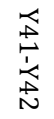 & $\begin{array}{l}\underset{\mathfrak{d}}{N} \\
\stackrel{\rightleftarrows}{\omega}\end{array}$ & 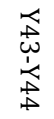 & 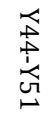 \\
\hline Accurate & + & + & - & + & + & + & - & + & - & + & - & + & - & - & + & - \\
\hline Interval & + & + & - & + & + & - & - & + & - & + & + & + & - & - & + & + \\
\hline
\end{tabular}

Based on the arrangement of Eqs. (13-15), we present details of productivity measurement in Table 2 as follows,

\section{Table 2}

The summary of productivity trend of firm B in different periods

Next, we present the trend of productivity using crisp and interval data and using Eqs. (7-0) we measure the trend and report them in Eqs. (16-18) and Table 3 as follows, 


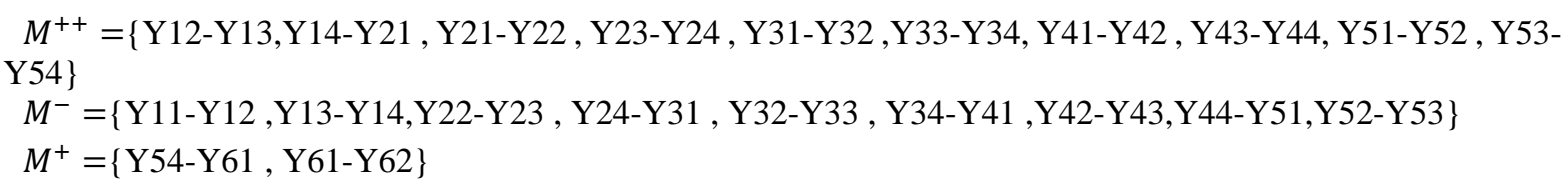

\section{Table 3}

The summary of productivity trend of firm $\mathrm{C}$ in different periods

\begin{tabular}{|c|c|c|c|c|c|c|c|c|c|c|c|c|c|c|c|c|c|c|c|c|c|}
\hline & 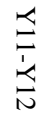 & 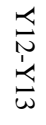 & 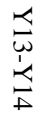 & 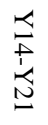 & $\begin{array}{l}\underset{N}{N} \\
\underset{N}{\sim}\end{array}$ & $\begin{array}{l}\underset{N}{N} \\
\stackrel{N}{N} \\
\text { N }\end{array}$ & 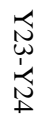 & 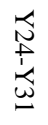 & 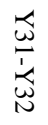 & 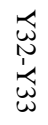 & 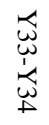 & 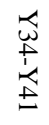 & 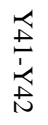 & 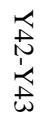 & 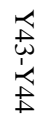 & 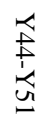 & 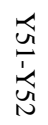 & 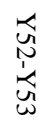 & 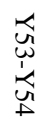 & 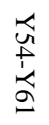 & 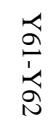 \\
\hline Accurate data & - & + & - & + & + & - & + & - & + & - & + & - & + & - & + & - & + & - & + & - & + \\
\hline Interval data & - & + & - & + & + & - & + & - & + & - & + & - & + & - & + & - & + & - & + & - & + \\
\hline
\end{tabular}

The results of Table 3 for accurate and Interval data, both, are the same of this unit. In other words, data uncertainty did not influence on the performance measurement of this firm. Finally, we present the results of performance measurement using Malmquist, which are presented in Eqs. (19-21) and Table 4 as follows,

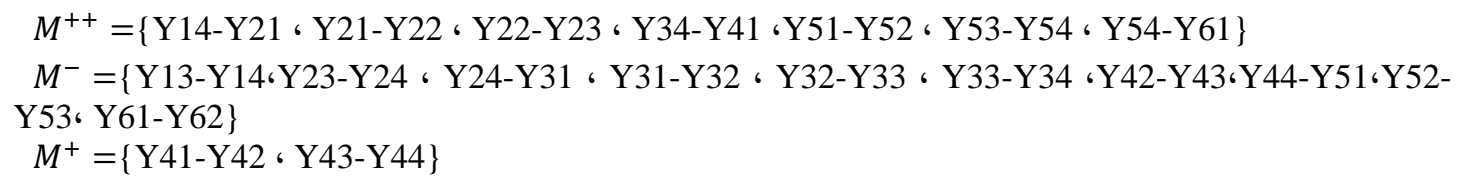

\section{Table 4}

The summary of productivity trend of firm D in different periods

\begin{tabular}{|c|c|c|c|c|c|c|c|c|c|c|c|c|c|c|c|c|c|c|c|}
\hline & 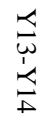 & 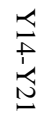 & $\underset{⿱ N}{\stackrel{N}{N}}$ & $\begin{array}{l}\underset{N}{N} \\
\stackrel{N}{N}\end{array}$ & 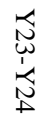 & 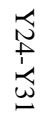 & 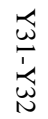 & 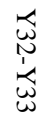 & 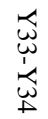 & 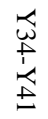 & 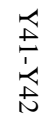 & 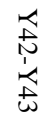 & 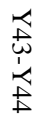 & 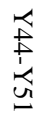 & 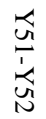 & 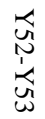 & 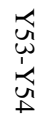 & 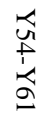 & 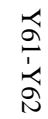 \\
\hline Accurate & - & + & + & + & - & - & - & - & - & + & - & - & - & - & + & - & + & + & - \\
\hline Interval & - & + & + & + & - & - & - & - & - & + & - & - & - & - & + & - & + & + & - \\
\hline
\end{tabular}

Similar to the results of Table 3, both accurate and interval data have yielded the same results for performance measurement.

\section{Discussion and conclusion}

In this paper, we have presented a hybrid of DEA and Malmquist techniques for performance measurement in four different units of a particular company over different three-month period. The proposed study has applied data interval method for handling data uncertainty associated with different data. The implementation of the proposed method has indicated that one could easily follow up different upward/downtrend in the system. This could help management team detect any possible shortcoming in the system and provide possible solution strategies. The results of this survey are consistent with other existing works in the literature (Aparicio et al., 2013; Ahn \& Min, 2014; Gharneh et al., 2014; Kerstens \& Van de Woestyne, 2014).

\section{Acknowledgement}

The authors would like to thank the anonymous referees for constructive comments on earlier version of this paper. 


\section{References}

Ahn, Y. H., \& Min, H. (2014). Evaluating the multi-period operating efficiency of international airports using data envelopment analysis and the Malmquist productivity index. Journal of Air Transport Management, 39, 12-22.

Aparicio, J., Pastor, J. T., \& Zofio, J. L. (2013). On the inconsistency of the Malmquist-Luenberger index. European Journal of Operational Research,229(3), 738-742.

Banker, R. D., Charnes, A., \& Cooper, W. W. (1984). Some models for estimating technical and scale inefficiencies in data envelopment analysis. Management science, 30(9), 1078-1092.

Caves, D. W., Christensen, L. R. \& Diewert, W. E., (1982). Multilateral comparisons of output, input, and productivity using superlative index numbers. Economic Journal, Royal Economic Society, 92(365), 73-86.

Charnes, A., Cooper, W. W., \& Rhodes, E. (1978). Measuring the efficiency of decision making units. European Journal of Operational Research, 2(6), 429-444.

Fuentes, R., \& Lillo-Bañuls, A. (2015). Smoothed bootstrap Malmquist index based on DEA model to compute productivity of tax offices. Expert Systems with Applications, 42(5), 2442-2450.

Gharneh, N. S., Nabavieh, A., Gholamiangonabadi, D., \& Alimoradi, M. (2014). Productivity change and its determinants: Application of the Malmquist index with bootstrapping in Iranian steam power plants. Utilities Policy, 31, 114-120.

Kerstens, K., \& Van de Woestyne, I. (2014). Comparing Malmquist and Hicks-Moorsteen productivity indices: Exploring the impact of unbalanced vs. balanced panel data. European Journal of Operational Research, 233(3), 749-758.

Lin, B., \& Du, K. (2015). Modeling the dynamics of carbon emission performance in China: A parametric Malmquist index approach. Energy Economics, 49, 550-557.

Rezitis, A. N. (2006). Productivity growth in the Greek banking industry: a non parametric approach. Journal of Applied economics, 9, 119-138.

Tulkens, H. (1993). On FDH efficiency analysis: some methodological issues and applications to retail banking, courts, and urban transit. Journal of Productivity Analysis, 4, 183-210.

Wijesiri, M., \& Meoli, M. (2015). Productivity change of microfinance institutions in Kenya: A bootstrap Malmquist approach. Journal of Retailing and Consumer Services, 25, 115-121.

Woo, C., Chung, Y., Chun, D., Seo, H., \& Hong, S. (2015). The static and dynamic environmental efficiency of renewable energy: A Malmquist index analysis of OECD countries. Renewable and Sustainable Energy Reviews, 47, 367-376.

Zhang, N., Zhou, P., \& Kung, C. C. (2015). Total-factor carbon emission performance of the Chinese transportation industry: A bootstrapped non-radial Malmquist index analysis. Renewable and Sustainable Energy Reviews, 41, 584-593. 